\title{
Editorial
}

Respiration

Respiration 2005;72:575-576

DOI: $10.1159 / 000089569$

\section{Chronic Obstructive Pulmonary Disease beyond Cigarette Smoke}

\author{
M. Marvisi G. Civardi \\ Department of Internal Medicine, Fiorenzuola d'Arda Hospital, Piacenza, Italy
}

Although cigarette smoking is the major risk factor for the development of chronic obstructive pulmonary disease (COPD), only $15-20 \%$ of all smokers develop airway obstruction, therefore not all smokers acquire COPD, and COPD can develop in non-smokers [1].

Unfortunately, in COPD, as in many other conditions, a complete description of the molecular components that encode a particular phenotype would not allow for a complete understanding of the disease without taking into account the influence of other factors such as environment. COPD, like asthma, seems to be a multigenic disease, and in the literature there are many essays pinpointing a specific genetic determinant of airway function as well as a predisposing factor that may confer susceptibility to COPD: $\alpha_{1}$-antitrypsin deficiency (PiMZ and PiMM genotype), and polymorphisms in matrix metalloproteinases 1 and 12 genes, the tumor necrosis factor- $\alpha$ gene promoter and in the antioxidant genes glutathione S-transferase (GSTM1, GSTT1, GSTP1), only to mention a few [2].

In recent years, epidemiological observations suggesting that childhood viral infections are an independent risk factor for the development of COPD in adulthood have increased the interest in virus infections, in particular group $\mathrm{C}$ adenovirus, which is endemic and could lead to latent infections that persist in tonsils, peripheral blood lymphocytes and above all in lung epithelial cells [3]. The E1A gene, where the E stands for the fact that it is one of a group of genes transcribed early in the viral life cycle, is responsible for enhancing host inflammatory mediator expression, because its products are transactivators that function by interacting with numerous cellular transcription factors, transcriptional coactivators and cell-cycleregulatory proteins. Furthermore, the E1A gene has been found to be integrated at a specific site on chromosome 19 in the lung cells of patients with COPD, and in patients with severe emphysema there is a fivefold increase in the number of alveolar epithelial cells expressing E1A protein $[2,3]$. These observations have led to a working hypothesis that the chronic expression of E1A might amplify the cigarette-smoke-induced inflammatory process. Keicho et al. [4] demonstrated that E1A enhances the expression of IL-8 and intracellular adhesion molecules 1 after lipopolysaccharide stimulation through the modulation of nuclear factor- $\mathrm{B}$ activity.

In this issue of Respiration, Higashimoto et al. [5] add another important element to the understanding of the protean mechanism of adenoviral-E1A-enhancing airway inflammation. The authors successfully demonstrate an E1A-mediated suppression of secretory leukoprotease inhibitor (SLPI) and elafin/skin-derived antileukoproteinase (two protease inhibitors) produced by airway epithe-

\section{KARGER}

Fax +4161306 1234

E-Mail karger@karger.ch

www.karger.com
(C) 2005 S. Karger AG, Basel

0025-7931/05/0726-0575\$22.00/0

Accessible online at:

www.karger.com/res
Maurizio Marvisi, MD

Department of Internal Medicine

Fiorenzuola d'Arda Hospital

Via Roma 9, Piacenza (Italy)

Tel. +390523989 640, Fax +390523989 649, E-Mail mmarvis@aliceposta.it 
lial cells, which play a major physiologic role in conferring antineutrophilic elastase protection. Furthermore, they point out that the E1A gene works not only by modulating nuclear factor- $\mathrm{\kappa B}$, but that it also suppresses SLPI transcription by affecting interferon-regulatory factor binding activity. The topic is intriguing and will doubtless undergo remarkable development in the next few years.
However, at this juncture two questions need a rapid answer. What is the potential role for other viruses, such as $\mathrm{HCV}$, in increasing the risk for the development of COPD? Is there a role for antiviral drugs, above all interferon, in treating COPD patients with latent viral infections?

\section{References}

1 Hayashi S: Latent adenovirus infection in COPD. Chest 2002;121:183S-187S

2 Morfino NA: Genetics of COPD. Chest 2004; 125:1929-1940.

3 Hogg JC: Role of latent viral infections in COPD and asthma. Am J Respir Crit Care Med 2001;164:S71-S75.
4 Keicho N, Higashimoto Y, Bondy GP, Elliott WM, Hogg JC, Hayashi S: Endotoxin-specific $\mathrm{NF}-\kappa \mathrm{B}$ activation in pulmonary epithelial cells harboring adenovirus E1A. Am J Physiol 1999; 277:L523-L532.
5 Higashimoto Y, Yamagata Y, Iwata T, Ishiguchi T, Okada M, Masuda M, Satoh H, Itoh H: Adenoviral E1A suppresses secretory leukoprotease inhibitor and elafin secretion in human alveolar epithelial cells and bronchial epithelial cells. Respiration 2005;72:629-635. 